\title{
Collas e cambas do outro lado da fronteira: aspectos da distribuição diferenciada da imigração boliviana em Corumbá, Mato Grosso do Sul
}

\author{
Sylvain Souchaud* \\ Rosana Baeninger**
}

\begin{abstract}
Este estudo busca apresentar os resultados da pesquisa de campo acerca dos bolivianos residentes na cidade de Corumbá-MS, destacando suas características. Procurou-se captar os diferenciais da imigração boliviana para a cidade de Corumbá, identificando aspectos culturais, territoriais e etno-lingüísticos das áreas de origem que se refletem nos diferenciais sociodemográficos existentes - entre um mesmo contingente imigrante - no lugar de destino: Corumbá/Brasil. Tais aspectos constituem fatores importantes para a leitura da própria configuração urbana da localização da imigração boliviana em Corumbá.
\end{abstract}

Palavras-chave: Migração internacional. Fronteira. Bolivianos.

\section{Introdução}

Com o objetivo de apreender os processos envolvidos nos movimentos migratórios da população boliviana na fronteira Santa Cruz/Bolívia-Corumbá/Brasil, foram utilizados os resultados do levantamento de campo realizado, em novembro de 2006 , no município de Corumbá, no âmbito do Projeto Espaços Migratórios e a Problemática Ambiental no Mercosul, financiado pelo $\mathrm{CNPq} / \mathrm{IRD}$-França. Neste texto privilegiou-se a migração boliviana para este espaço de fronteira, por se tratar de processo migratório antigo no Município de Corumbá, mas que revela - atualmente em seus fluxos - novas conformações, composições e redes denotando perfis socioeconômicos e culturais diferenciados no âmbito do próprio contingente de migrantes bolivianos.
Os dados da pesquisa permitem considerar vários segmentos de bolivianos migrantes. Para este texto, foram focalizadas as populações nascidas na Bolívia, recentemente entrevistadas em Corumbá. O levantamento de campo possibilita identificar o departamento de nascimento da população boliviana residente em Corumbá, aspecto somente captado por uma pesquisa desta natureza, uma vez que com os dados censitários é possível apenas identificar o país de nascimento dos estrangeiros no Brasil.

É com essas informações que o presente trabalho busca captar os diferenciais da imigração boliviana para a cidade de Corumbá, procurando identificar aspectos culturais, territoriais e etno-lingüísticos característicos das áreas de origem, que se refletem nos diferenciais sociodemográficos existentes entre um mesmo contingente

\footnotetext{
* Geógrafo, pesquisador do Institut de Recherche pour le Développement (IRD) e Núcleo de Estudos de População Nepo/, Unicamp.

** Professora do Departamento de Demografia - IFCH e pesquisadora do Núcleo de Estudos de População - Nepo/ Unicamp.
} 


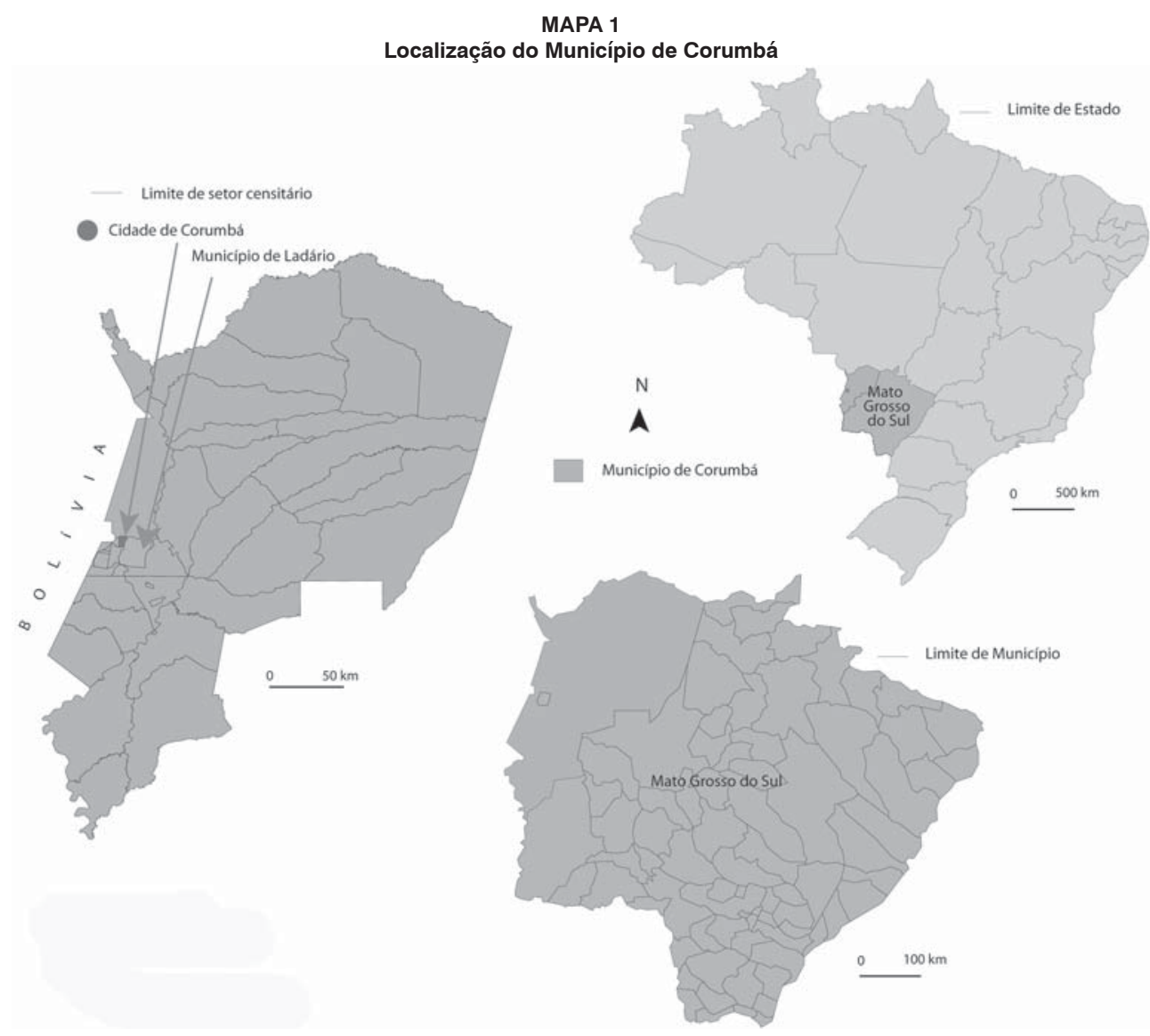

Fonte: IBGE. Censo Demográfico 2000.

imigrante no lugar de destino, no caso Corumbá/Brasil. Esses diferenciais constituem fatores importantes para a leitura da própria configuração urbana e identificação dos espaços diferenciados da migração boliviana na cidade.

\section{Collas e cambas: fundamentos e alcance da distinção}

Em 2001, segundo o Censo boliviano, $62,1 \%$ da população de 15 anos e mais (3.142.828 pessoas) se autodesignava como nativa, sendo $30,7 \%$ quíchuas (1.555.459), $25,2 \%$ aimaras (1.277.897), $1,6 \%$ guaranis (78.507), 2,2\% chiquitanos (112.443), 0,9\% mojeños (43.052) e 1,5\% de outros grupos nativos (75.468).
Historicamente, a distribuição desses grupos no país segue uma diferenciação geográfica elementar entre regiões montanhosas e planícies das regiões baixas. Nas primeiras, encontravam-se os aimaras e quíchuas; nas segundas, os outros povos nativos (BLANCHARD, 2005). Esse fato é reforçado por diferenças culturais importantes: as civilizações andinas formaram parte do Império Inca, que se distingue por sua alta estruturação tanto social (estrutura fortemente hierarquizada), a qual permitiu a integração de vários povos andinos, quanto espacial (urbanização, infra-estruturas de comunicação). Assim, desde larga data, existe uma forte diferenciação entre a civilização andina - estruturada e integrada pelo Império Inca - e o mosaico étnico das 
regiões baixas, composto por povos menos numerosos e mais dispersos, organizados em sistemas sociais não tão marcados pela expansão e o controle territorial duradouro. Esses dois tipos de modelos territoriais são simbolizados pela presença/ausência da cidade. Isto é importante nos Andes, pois a civilização inca é antes de tudo urbana (Cuzco, que significa umbigo em quíchua, era sua capital); a cidade não existe nas regiões baixas fora das "importações" incas.

O termo collas - que hoje existe na oposição aos cambas - deriva dessa distribuição e diferenciação histórica e pré-colombiana (BLANCHARD, 2005). Assim, o termo colla derivaria da palavra collasuyo, que designava um dos quatro setores (distritos) do Império Inca, o qual correspondia, grosso modo, à atual região andina da Bolívia. Hoje, a palavra colla designa os que são ou vêm do altiplano, isto é, os aimaras e quíchuas (BLANCHARD, 2005). Por contraste e na origem, os cambas são os membros das comunidades nativas das regiões baixas, principalmente guaranis e chiquitanos.

Hoje, a oposição entre os dois termos cristaliza a profunda e violenta crise que o país vem atravessando. Ela define-se na base de elementos políticos e econômicos e se expressa num antagonismo entre o ocidente e o oriente, equivalente à oposição entre as regiões altas (andinas, altiplânicas) e baixas, ou seja, entre cambas e collas (BLANCHARD, 2005).

Nos últimos 50 anos, as regiões orientais conheceram um forte desenvolvimento vinculado aos setores agrícola, industrial e energético (as reservas de petróleo e gás estão no oriente), liderado pela cidade de Santa Cruz de la Sierra, que hoje é o maior pólo econômico do país e centro demográfico de primeira importância (SOUCHAUD, 2007). A transferência das centralidades, ou pelo menos o re-equilíbrio a favor do oriente, se fez sem transferência dos poderes políticos. Desse modo, hoje, o oriente, liderado por Santa Cruz de la Sierra, contesta o histórico predomínio político de La Paz e, de forma mais geral, da região andina, sobre o país, pedindo a autonomia de departamentos orientais.

Como qualquer marcador identitário fortemente reivindicado, o emprego da palavra colla (sempre usada pelos cambas) adequa-se mal à realidade, mas expressa tensões sociais profundas (BLANCHARD, 2005) que, no caso boliviano, assumem formas territoriais.

\section{A redistribuição da população boliviana no território nacional: o papel de Santa Cruz}

A situação, hoje, torna-se mais complexa, pois nos últimos 50 anos, além desse re-equilíbrio - que, de certa forma, justifica adaptações nas formas e no exercício do poder -, ocorreu o encontro desses dois universos culturais: o do ocidente e o do oriente, numa relação de desigualdade, com a formação do estigma. Esse "encontro" deveu-se graças a um histórico processo de redistribuição da população (BLANCHARD, 2005). Nesse sentido, cabe aqui insistir no papel específico do departamento de Santa Cruz e sua capital Santa Cruz de la Sierra para a compreensão dos processos internos de reorganização populacional.

A população do departamento de Santa Cruz cresceu a uma taxa geométrica anual de 4,33\% em 25 anos, passando de 697.245 para 2.010.445 habitantes, entre 1976 e 2001. No mesmo período, a população da capital experimentou uma taxa de crescimento de $6,08 \%$ ao ano, passando de 254.682 para 1.113 .582 habitantes.

Esse crescimento foi possível pela migração de moradores de departamentos do altiplano (SOUCHAUD, 2007). Em 2001, 26,7\% dos habitantes de Santa Cruz eram nascidos em outro departamento. O fenômeno é também muito forte na atualidade, já que, dos cerca de 424 mil indivíduos (maiores de 5 anos de idade) que mudaram de departamento de residência, entre 1996 e $2001,34,5 \%$ (146.500) dirigiram-se para Santa Cruz. Este departamento contava com $24,5 \%(2.029 .471)$ da população nacional, ${ }^{1}$ em 2001, que correspondia a 8.274.325

\footnotetext{
1 Em 1976 e 1992, o Departamento de Santa Cruz representava, respectivamente, 15,4\% e 21,3\% da população do país.
} 
habitantes. Ao se considerar o local de nascimento dos residentes, em 2001, no departamento de Santa Cruz, verifica-se que 9,1\% (182.765) nasceram nos departamentos andinos de La Paz, Potosí e Oruro. ${ }^{2}$ Essa imigração andina, provavelmente, teria uma proporção mais forte na cidade de Santa Cruz de la Sierra.

Outra forma de identificar esse processo de mudança das fronteiras culturais dentro da Bolívia é considerando o pertencimento a grupos nativos segundo departamento de residência. Há algumas décadas, a distribuição étnica no país estava geograficamente marcada: o altiplano era o lugar dos quíchuas e aimaras (os aimaras concentrandose mais em La Paz); as planícies do oriente abrigavam as outras populações indígenas, muito menos numerosas. Contudo, essa segmentação espacial ainda persiste, uma vez que os guaranis, chiquitanos, mojeños e outros nativos do oriente ainda são pouco representados nos departamentos andinos; da mesma forma, os quíchuas e aimaras ainda são nitidamente sub-representados no oriente. Em Santa Cruz, departamento do oriente, entretanto, nota-se maior diversidade étnica, com importantes proporções de cada grande grupo étnico. Os quíchuas, por exemplo, representam $17 \%$ da população do departamento - valor muito acima do que se observa nos departamentos onde predomina a planície; os chiquitanos, outro exemplo, correspondem a $8,8 \%$ da população (DOMENACH, 2007).

Nesse contexto, o departamento de Santa Cruz, da mesma forma que acontece nos departamentos não andinos, ainda mantém um baixo nível de identificação de sua população com grupos nativos: $37,5 \%$, em contraposição aos 77,5\% em La Paz e 83,5\% em Potosí. Apesar disso, o departamento de Santa Cruz é muito mais diversificado etnicamente que qualquer outro departamento boliviano.

É nesse cenário de transformações culturais, identitárias e migrações internas, aqui brevemente indicado que partem da Bolívia seus emigrantes para o Brasil.

\section{Os bolivianos no Brasil e a polarização da imigração na fronteira}

A comunidade nascida na Bolívia e residente no Brasil tem apresentado aumento em anos recentes (SOUCHAUD; BAENINGER, 2008). Em 2000, o censo demográfico brasileiro registrava 20.388 imigrantes bolivianos, quando em 1991 eram 15.694, indicando uma taxa de crescimento de $2,41 \%$ ao ano nesse período. Ressalte-se, contudo, que uma parte significativa da população boliviana escapa aos censos.

A localização espacial da população nascida na Bolívia e residente no Brasil, em 2000, pode ser observada no Mapa 2. Elementos importantes podem ser identificados, destacando-se:

- presença boliviana em todos os estados brasileiros, com exceção do Amapá;

- distribuição da imigração boliviana de maneira mais significativa nas áreas de fronteira e nas regiões metropolitanas de São Paulo e do Rio de Janeiro;

- maior concentração da população migrante boliviana - fora dos espaços de fronteira - em espaços do Sudeste, em particular nas metrópoles;

- tendência à aglomeração de bolivianos em alguns municípios fronteiriços, ou seja, os imigrantes se concentram em poucos lugares: Guajará-Mirim e Porto Velho, em Rondônia e Corumbá, no Mato Grosso do Sul.

Essa forte polarização na zona de fronteira é característica da migração boliviana e, de certa forma, obedece às configurações territoriais das faixas de fronteira de cada país. O fraco povoamento da área, que

\footnotetext{
2 A zona andina se estende além desses departamentos, mas esses três são exclusivamente andinos, diferentemente do departamento de Cochabamba, por exemplo, que associa zona andina e vales, o que dificulta a classificação de seus moradores. A proporção chega a 15,2\% quando se incluem o nascidos em Cochabamba.
} 


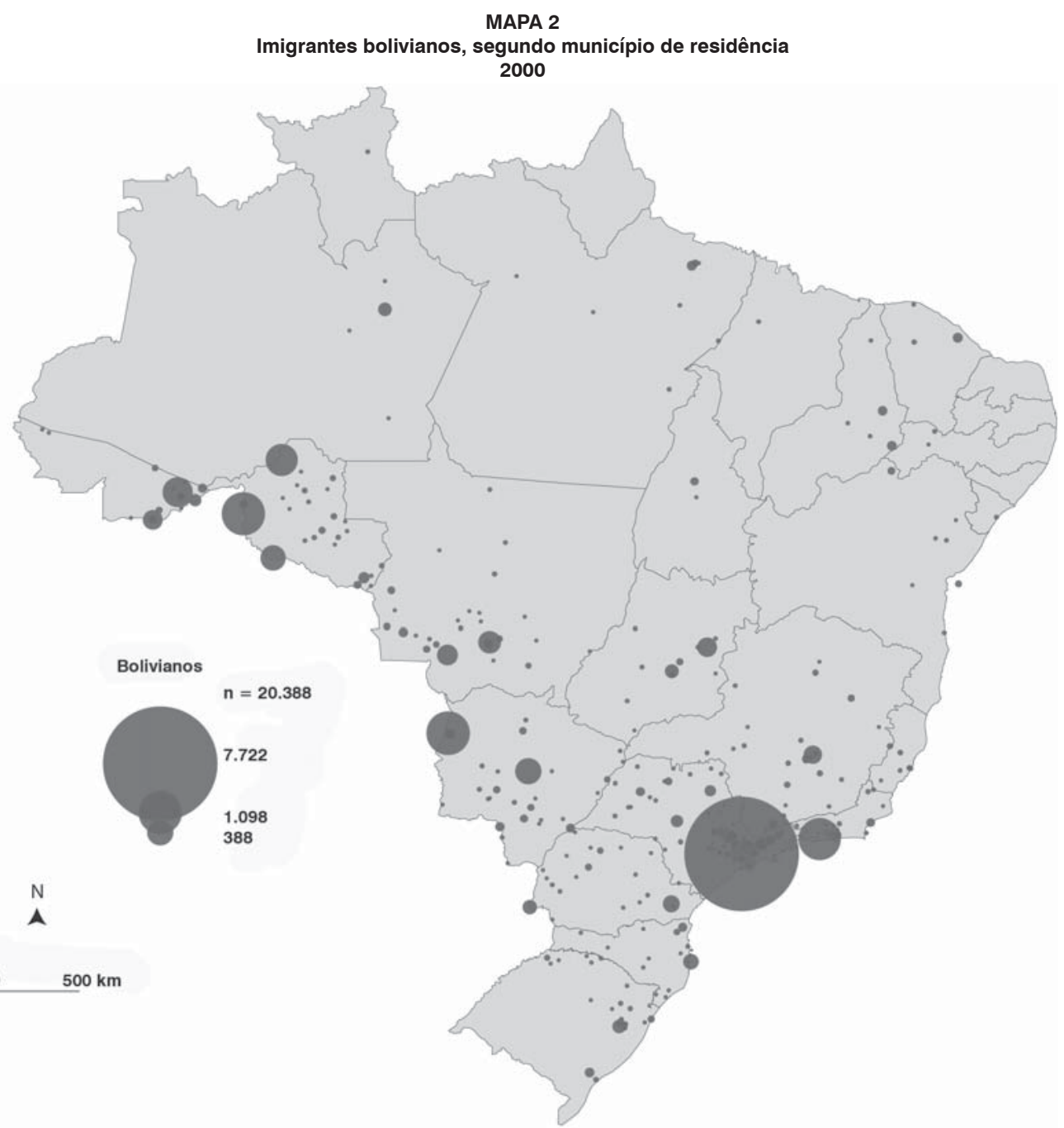

\begin{tabular}{lcc} 
& Dez principais localidades & \\
\hline Município de residência & Bolivianos & $\%$ \\
\hline São Paulo (SP) & 7.722 & 37,9 \\
Corumbá (MS) & 1.098 & 5,4 \\
Guajará-Mirim (RO) & 1.077 & 5,3 \\
Rio de Janeiro (RJ) & 1.020 & 5,0 \\
Porto Velho (RO) & 583 & 2,9 \\
Rio Branco (AC) & 507 & 2,5 \\
Campo Grande (MS) & 388 & 1,9 \\
Guarulhos (SP) & 367 & 1,8 \\
Costa Marques (RO) & 360 & 1,8 \\
Cuiabá (MT) & 283 & 1,4 \\
Subtotal & $\mathbf{1 3 . 4 0 5}$ & $\mathbf{6 5 , 7}$ \\
\hline Total & $\mathbf{2 0 . 3 8 8}$ & $\mathbf{1 0 0 , 0}$ \\
\hline
\end{tabular}

Fonte: IBGE. Censo Demográfico, 2000. Souchaud/IRD 2006.

Philcarto http://philgeo.club.fr. 
corresponde à fronteira com a Bolívia, e as descontinuidades específicas da distribuição da população brasileira nessa região se reproduzem na repartição da imigração boliviana na localidade. Ou seja, no município de Corumbá, os bolivianos se concentram na área urbana, da mesma forma que os brasileiros.

A imensidão da fronteira do Brasil com a Bolívia se caracteriza por descontinuidades importantes, que associam vastas áreas pouco ocupadas e integradas a lugares altamente integrados.

O município de Corumbá ilustra essa situação contrastante, já que é um território de $64.961 \mathrm{~km}^{2}$, com aproximadamente 200 $\mathrm{km}$ de fronteira com a Bolívia (Mapa 1). Em 2007, a população era de 96.373 habitantes, dos quais 86.656 (89,9\% do total) moravam na área urbana de Corumbá, a poucos quilômetros da fronteira internacional. Com uma população, em 2000, de 9.717 habitantes e uma densidade populacional de 0,15 hab./ $\mathrm{km}^{2}$, a área rural do município de Corumbá ainda pode ser considerada uma margem pouco integrada. Em contraste, a cidade de Corumbá aparece como um pontochave dentro das trocas e da dinâmica de integração no subcontinente (OLIVEIRA, 1998). A cidade é um lugar estratégico de articulação dos fluxos de bens, pessoas e informações, configurando o denominado corredor bi-oceânico, que agrega as duas margens litorâneas do continente, isto é, o sudeste brasileiro com os portos peruanos e chilenos do Pacífico, passando pelo eixo de concentração do povoamento boliviano Santa Cruz-Cochabamba-La Paz.

A concentração da imigração boliviana em poucos lugares faz com que sua presença seja muito mais marcante e visível, em relação à de outros contingentes migrantes estrangeiros no Brasil. ${ }^{3}$ Observa-se que a maior concentração dos bolivianos ocorre no município de São Paulo, onde se encontram $38 \%$ do total de imigrantes dessa nacionalidade (SOUCHAUD; BAENINGER, 2007).

Com relação à imigração boliviana em Corumbá, é importante ressaltar que o censo demográfico de 2000 registrou 789 domicílios com presença boliviana (mesmo que os filhos ou cônjuges sejam brasileiros), representando $3,4 \%$ do total dos domicílios e englobando uma população de 3.240 pessoas.

\section{Características da população boliviana em Corumbá: a importância do lugar de nascimento na diferenciação dos grupos imigrantes}

As análises a seguir constam da base de dados Encor- Encuesta Corumbá -Nepo/Unicamp-IRD/França e referem-se à população nascida na Bolívia e residente em Corumbá em 2006, correspondendo a 362 pessoas. ${ }^{4}$ Para este estudo, os nove departamentos da Bolívia foram agrupados em Terras Baixas e Terras Altas. As primeiras reúnem os departamentos de Santa Cruz, Beni Pando e Tarija, enquanto as Terras Altas englobam os departamentos de La Paz, Potosí, Oruro, Chuquisaca e Cochabamba. ${ }^{5}$ Tal agrupamento corresponde aproximadamente à distinção entre oriente e ocidente e entre quíchuas e aimaras, bem como à polêmica distinção entre cambas e collas.

A pesquisa Encor permite determinar tanto características culturais individuais, tais como as línguas nativas praticadas, quanto a origem geográfica dos imigrantes. Assim, verifica-se que os principais grupos etno-lingüísticos da Bolívia (quíchuas, aimaras, guaranis) são representados em Corumbá. Por outra parte, observa-se que as diferenciações lingüísticas correspon-

\footnotetext{
${ }^{3}$ No caso da imigração dos paraguaios para o Brasil, Souchaud (2006a) indica sua elevada dispersão espacial.

4 O critério de seleção não foi ter nascido na Bolívia, mas sim o departamento de nascimento na Bolívia, sendo que duas pessoas nascidas na Bolívia não declararam departamento de nascimento.

5 Uma dúvida existe para Cochabamba, que geograficamente pertence ao oriente e ocidente, ao pé de monte e ao planalto. Verificou-se que os bolivianos que vêm de lá pertencem à região alta do departamento: os 28 imigrantes provenientes deste departamento nasceram num município cuja sede fica a mais de 2.205 metros de altitude. Com esse critério geográfico presente, atentou-se para o aspecto etno-linguístico: dos 28 naturais daquela região, 17 falam quíchua e um aimara. Assim, para este estudo, decidiu-se classificar o departamento de Cochabamba na região alta.
} 
dem à segmentação mencionada entre regiões baixas e regiões altas. Nas Terras Baixas não há predomínio lingüístico; já nas Terras Altas são importantes as participações de quíchua e aimara como línguas nativas faladas.

Nesse sentido, podem ser apontadas características deste heterogêneo grupo imigrante em Corumbá, que são apresentadas a seguir.
Diferencial na distribuição espacial dos bolivianos no contexto urbano de Corumbá

Considerando os imigrantes bolivianos captados pela pesquisa na cidade de Corumbá (Mapa 3), em 2006, 75,7\% declararam ter nascido em departamentos que compõem as Terras Baixas da Bolívia e $24,3 \%$ nas Terras Altas. Essa diferenciação regional na origem dos bolivianos já indica

TABELA 1

Imigrantes bolivianos, por localidade de origem, segundo língua nativa falada Município de Corumbá - 2006

\begin{tabular}{lccc}
\hline \multicolumn{1}{c}{ Língua nativa } & Terras Baixas & Terras Altas & Total \\
\hline Nenhuma & 231 & 31 & 262 \\
Quíchua & 16 & 37 & 53 \\
Aimara & 0 & 20 & 20 \\
Guarani & 1 & 0 & 1 \\
Outras & 7 & 0 & 7 \\
Total & $\mathbf{2 5 5}$ & $\mathbf{8 8}$ & $\mathbf{3 4 3}$ \\
\hline
\end{tabular}

Fonte: Encor 2006. Nepo/Unicamp-IRD/França.

TABELA 2

Imigrantes bolivianos, por local de origem, segundo bairros de residência Município de Corumbá - 2006

\begin{tabular}{lccc}
\hline Bairros de residência & Terras Baixas & Terras Altas & Total \\
\hline Arthur Marinho & 6 & 8 & 14 \\
Generoso & 2 & 0 & 2 \\
Centro & 66 & 39 & 3 \\
Universitário & 3 & 0 & 23 \\
Maria Leite & 17 & 6 & 3 \\
Centro-América & 3 & 0 & 12 \\
Nossa Senhora de Fátima & 11 & 1 & 16 \\
Popular Velha & 14 & 2 & 30 \\
Aeroporto & 20 & 10 & 4 \\
Popular Nova & 4 & 0 & 80 \\
Cristo Redentor & 76 & 4 & 3 \\
Previsul & 3 & 0 & 14 \\
Jardim dos Estados & 10 & 4 & 9 \\
Guarani & 5 & 4 & 8 \\
Nova Corumbá & 7 & 1 & 6 \\
Guatós & 6 & 0 & 30 \\
Dom Bosco & 21 & 9 & $\mathbf{3 6 2}$ \\
Total & $\mathbf{2 7 4}$ & \\
\hline
\end{tabular}

Fonte: Encor 2006. Nepo/Unicamp-IRD/França. 
especificidades desta migração internacional, refletindo-se de maneira acentuada na própria distribuição, concentração e alocação deste contingente populacional em Corumbá.

De fato, a partir da Tabela 2 e dos Mapas 4, 5 e 6, verifica-se que, enquanto os bolivianos das Terras Altas estão bastante concentrados no centro $(44,3 \%)$, os imigran- tes oriundos das Terras Baixas estão mais dispersos na cidade e se distribuem entre o bairro Cristo Redentor (27,7\%) e o centro $(24,1 \%)$. Essa distribuição espacial dos bolivianos na cidade indica redes migratórias bastante distintas, uma vez que alguns bairros, além do centro, despontam como locais de bolivianos das Terras Altas, como Arthur Marinho (9\% do total dos bolivianos

MAPA 3

Localização dos bairros e das entrevistas realizadas em Corumbá em outubro de 2006

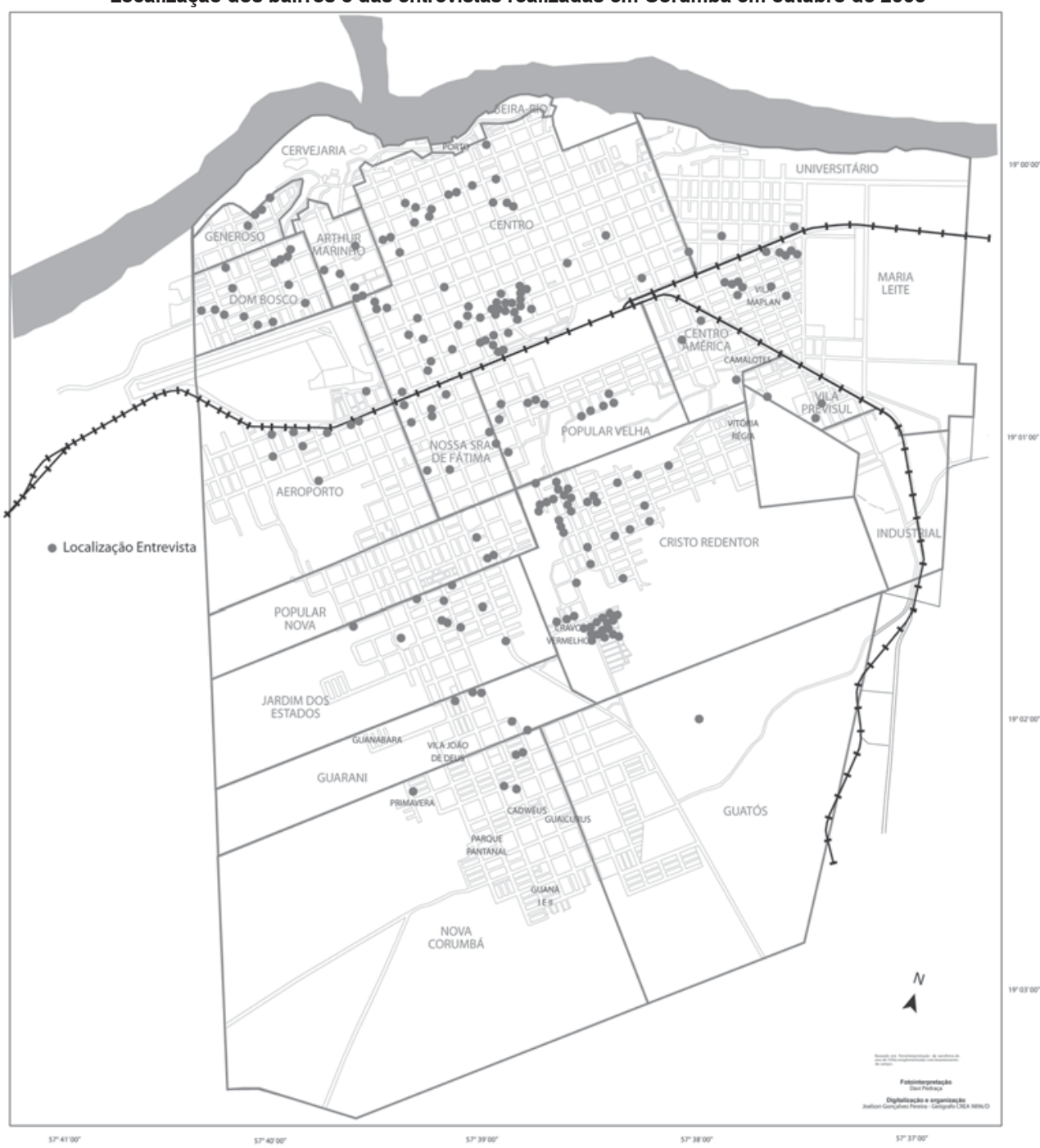

Fonte: Prefeitura Municipal de Corumbá, Unidade Executora Municipal - UEM. 
MAPA 4

População total e imigrantes bolivianos, segundo bairro de residência Município de Corumbá - 2000-2006

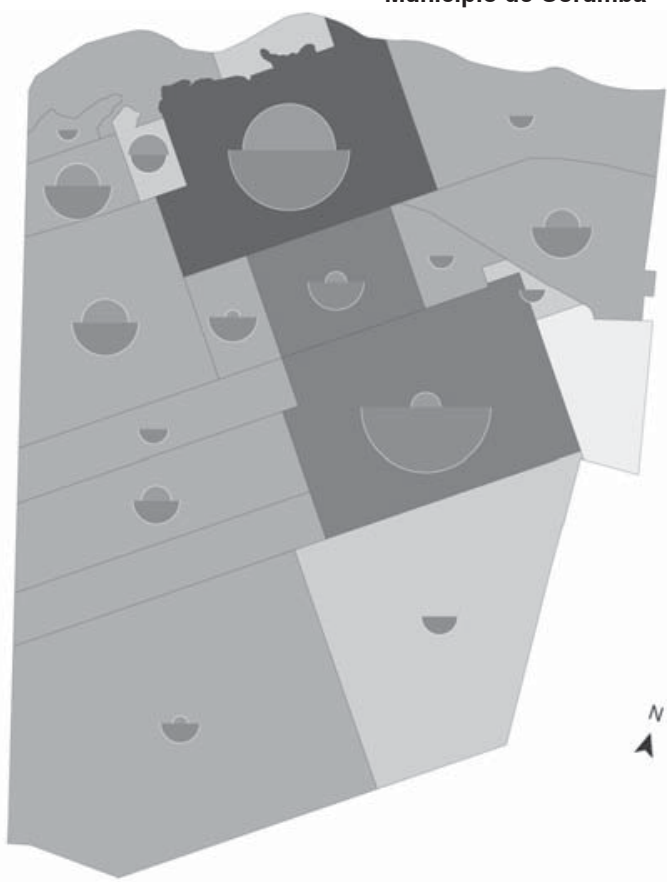

População total de Corumbá - 2000

Distribuiçāo por bairro (\%)

25,1

12,

$\mathrm{n}=8.447$

7,6
2,4

$\square, 3$

0.0

Imigrantes bolivianos - 2006

volume Tipo de lugar por nascimento

$76 \quad$ Terras altas

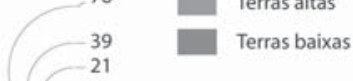

$\mathrm{n}=362$ (amostra)

$N$

$0 \quad 1 \mathrm{~km}$

Fonte: IBGE. Censo Demográfico 2000; Pesquisa Encor 2006. Nepo/Unicamp-IRD/França.

MAPA 5

Imigrantes bolivianos nascidos nas Terras Altas, segundo bairro de residência Município de Corumbá - 2006

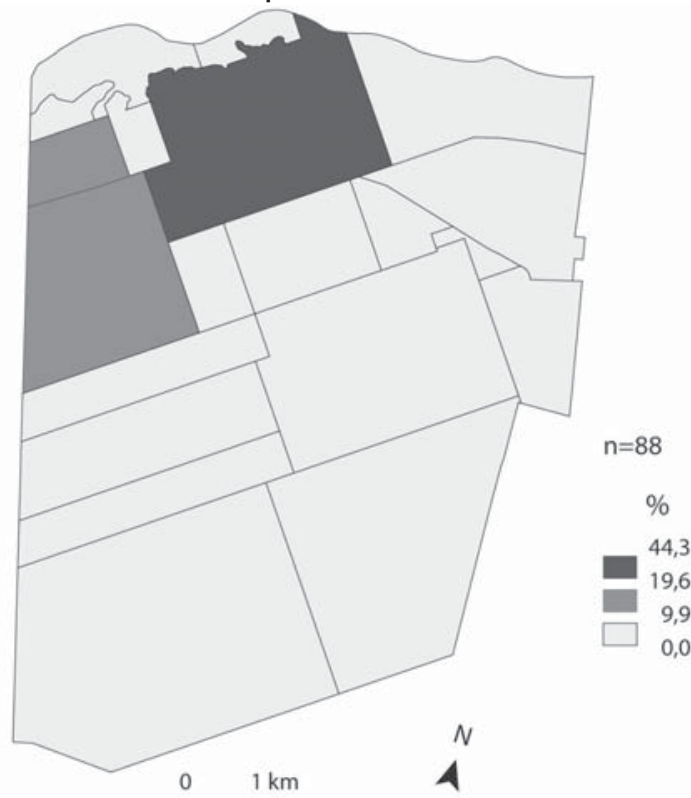

Fonte: IBGE. Censo Demográfico 2000; Pesquisa Encor 2006. Nepo/Unicamp-IRD/França. 
MAPA 6

Imigrantes bolivianos nascidos nas Terras Baixas, segundo o bairro de residência Município de Corumbá - 2006

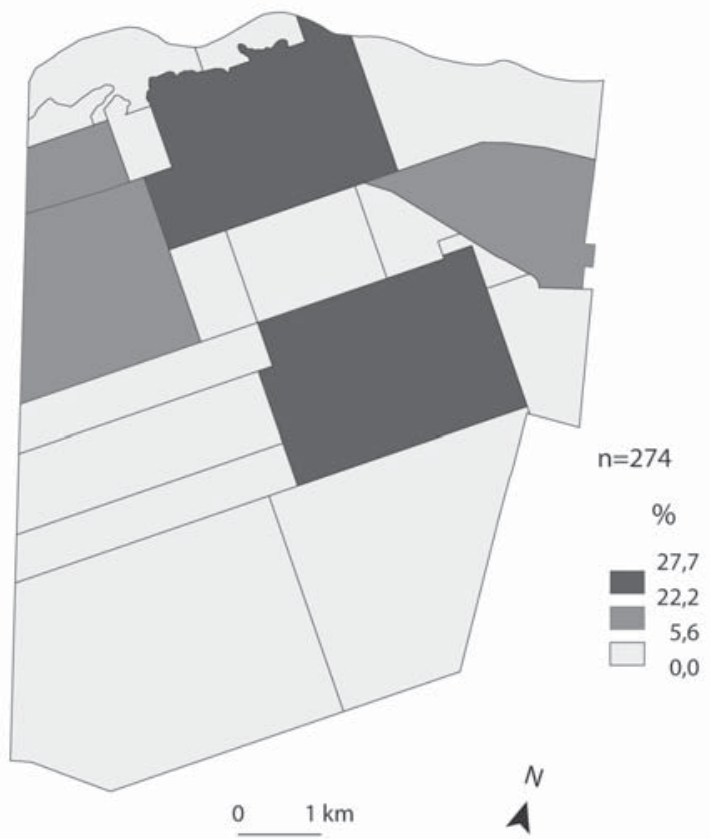

Fonte: IBGE. Censo Demográfico 2000; Pesquisa Encor 2006. Nepo/Unicamp-IRD/França.

das Terras Altas), enquanto outros bairros - como Popular Velha e Nossa Senhora de Fátima - possuem maior presença dos bolivianos das Terras Baixas.

Contudo, nota-se que alguns bairros apresentam proporções de bolivianos bastante próximas, parecendo indicar a emergência de um novo padrão espacial de alocação dessa migração na cidade, com a presença conjunta das duas origens migratórias, como são os casos dos bairros Maria Leite, Aeroporto e Dom Bosco, situados próximos à feira Brás-Bol, onde atuam muitos bolivianos, e, de forma geral, caracterizados por uma importante atividade comercial.

\section{Diferencial por sexo e idade na imigração boliviana}

Característica importante da imigração boliviana para Corumbá refere-se à elevada presença de mulheres: $63 \%$ contra $37 \%$ de homens. Esse diferencial é ainda mais reforçado quando se considera a origem de nascimento dos bolivianos. Entre os imigrantes provenientes das Terras Baixas, cerca de $67 \%$ são mulheres, alcançando o dobro da população de homens. Já para aqueles oriundos das Terras Altas, há um equilíbrio na razão de sexos.

Com relação à idade, a Tabela 4 mostra que os imigrantes bolivianos nascidos nas Terras Baixas constituem segmentos mais jovens, com importante participação do grupo de até 14 anos, podendo se estender ao grupo adulto de até 29 anos, bem como maior concentração de população nos grupos etários de 50-69 anos e de 30 a 49 anos, denotando um perfil migratório com famílias e filhos pequenos e jovens, além de a presença do grupo idoso ser bastante forte.

Já os imigrantes das Terras Altas concentram-se nas idades de 30 a 49 anos (mais da metade deste contingente imigrante), com pouca presença do grupo de até 14 anos, mas também com importante partici- 
pação do início do grupo adulto; o segmento idoso é pouco representativo entre os imigrantes bolivianos das Terras Altas.

\section{Diferencial de escolaridade na imigração boliviana}

Os imigrantes das Terras Altas apresentam níveis mais elevados de escolaridade do que aqueles nascidos nas Terras Baixas. Entre os primeiros, quase a metade dos entrevistados apresenta mais de dez anos de estudo, enquanto os bolivianos das Terras Baixas possuem níveis bem baixos de escolaridade. De fato, diferencial expressivo refere-se à proporção de imigrantes que não têm nenhum ano de estudo para os bolivianos das Terras Baixas. As proporções mais semelhantes estão entre 5 e 9 anos de estudo, para ambos contingentes de imigrantes.

Diferencias ocupacionais, tempo de residência e rendimentos dos imigrantes bolivianos em Corumbá

Os diferenciais de escolaridade existentes entre os bolivianos nascidos nas Terras Baixas e nas Terras Altas, apontados anteriormente, se refletem de maneira contundente nas ocupações dos bolivianos em Corumbá.

As atividades mais presentes entre os bolivianos das Terras Baixas são: "ama de casa"; doméstica/diarista/lavadeira/ cozinheira; trabalho em comércio familiar;

TABELA 3

Imigrantes bolivianos, por sexo, segundo local de origem Município de Corumbá - 2006

\begin{tabular}{lccc}
\hline Local de origem & Homens & Mulheres & Total \\
\hline Terras Baixas & 91 & 183 & 274 \\
Terras Altas & 43 & 45 & 88 \\
Total & $\mathbf{1 3 4}$ & $\mathbf{2 2 8}$ & $\mathbf{3 6 2}$ \\
\hline
\end{tabular}

Fonte: Encor 2006. Nepo/Unicamp-IRD/França.

TABELA 4

Imigrantes bolivianos, por local de origem, segundo grupos de idade Município de Corumbá - 2006

\begin{tabular}{lccc}
\hline Grupos de idade & Terras Baixas & Terras Altas & Total \\
\hline 0-14 anos & 29 & 5 & 34 \\
$15-29$ anos & 40 & 18 & 58 \\
$30-49$ anos & 68 & 51 & 119 \\
$50-69$ anos & 99 & 12 & 111 \\
70 anos e mais & 38 & 2 & 40 \\
Total & $\mathbf{2 7 4}$ & $\mathbf{8 8}$ & $\mathbf{3 6 2}$ \\
\hline
\end{tabular}

Fonte: Encor 2006. Nepo/Unicamp-IRD/França.

TABELA 5

Imigrantes bolivianos, por local de origem, segundo anos de estudo Município de Corumbá - 2006

\begin{tabular}{lccc}
\hline Anos de estudo & Terras Baixas & Terras Altas & Total \\
\hline Nenhum & 22 & 4 & 26 \\
1 -4 anos & 63 & 16 & 79 \\
$5-9$ anos & 99 & 31 & 130 \\
Não se aplica & 7 & 1 & 8 \\
Total & $\mathbf{2 7 4}$ & $\mathbf{8 8}$ & $\mathbf{3 6 2}$ \\
\hline
\end{tabular}

Fonte: Encor 2006. Nepo/Unicamp-IRD/França. 
atendentes em lojas/quitandas/feirante. Para aqueles provenientes das Terras Altas, há um predomínio nas ocupações feirante e dono de comércio familiar, sendo as atividades domésticas pouco representativas.

Esses diferenciais na estrutura ocupacional dos imigrantes bolivianos, segundo a origem de nascimento, refletem também a estrutura por sexo, em que a presença da mulher é bem mais expressiva entre os nascidos nas Terras Baixas e, portanto, mais acentuadas são as atividades voltadas para trabalhos domésticos.

Ressalte-se que a imigração dos bolivianos oriundos das Terras Baixas é mais antiga e, portanto, já apresenta importante participação de aposentados em seu contingente populacional.

De fato, mais de $40 \%$ das pessoas pertencentes a esse grupo têm tempo de residência superior a 30 anos em Corumbá, ou seja, uma imigração datada dos anos 70 e de décadas anteriores, com registros dos anos 50 (mais de 15\% desses imigrantes). As entradas mais recentes de bolivianos das Terras Baixas representam 18\% entrados entre 2001 e 2006 e $10 \%$ entre 1995 e 2000.

Já a seletividade da imigração dos bolivianos das Terras Altas é também marcada pelo menor tempo de residência em Corumbá: cerca de $36 \%$ chegaram nos anos
90; $22 \%$ no final da década de 80 ; e $17 \%$ entre 2001 e 2006.

A entrada recente dos imigrantes bolivianos, quer seja das Terras Altas quer seja das Terras Baixas, parece indicar novos aspectos da imigração boliviana em seu conjunto, podendo tender a aproximar as características dos contingentes provenientes das Terras Baixas com os das Terras Altas em um futuro próximo; a participação dos imigrantes entrados entre 2001 e 2006, no total de ambos contingentes migratórios, é bastante semelhante - em torno de $18 \%$.

O maior diferencial entre os contingentes de imigrantes bolivianos está na condição de ocupação, com elevada presença de empregados entre os nascidos nas Terras Baixas, ao passo que, para aqueles provenientes das Terras Altas, esta condição é pouco expressiva. Nas demais condições de ocupação - autônomo por conta própria, dono/trabalhador em negócio familiar -, os dois contingentes bolivianos imigrantes apresentam níveis próximos de inserção.

A inserção diferenciada no mercado de trabalho contribui para que o rendimento médio mensal dos bolivianos nascidos nas Terras Baixas esteja concentrado em até $\mathrm{R} \$ 350,00$, com cerca de $65 \%$ desses imigrantes com este rendimento mensal.

TABELA 6

Imigrantes bolivianos, por local de origem, segundo tempo de residência Município de Corumbá - 2006

\begin{tabular}{lccc}
\hline Tempo de residência & Terras Baixas & Terras Altas & Total \\
\hline Menos de 5 anos & 51 & 15 & 66 \\
De 5 a 9 anos & 28 & 23 & 51 \\
De 10 a 14 anos & 14 & 9 & 23 \\
De 15 a 19 anos & 22 & 20 & 42 \\
De 20 a 24 anos & 16 & 11 & 27 \\
De 25 a 29 anos & 17 & 3 & 20 \\
De 30 a 34 anos & 9 & 2 & 11 \\
De 35 a 39 anos & 17 & 0 & 17 \\
De 40 a 44 anos & 27 & 3 & 30 \\
De 45 a 49 anos & 20 & 0 & 20 \\
De 50 a 54 anos & 27 & 1 & 28 \\
55 anos e mais & 19 & 0 & 19 \\
Nao sabe & 7 & 1 & $\mathbf{3 6 2}$ \\
Total
\end{tabular}

Fonte: Encor 2006. Nepo/Unicamp-IRD/França. 
Entre 1 e 3 salários mínimos mensais (de $R \$ 351,00$ a $R \$ 1.050,00$ ) estão $25 \%$ dos bolivianos das Terras Baixas e, de 3 a 5 salários mínimos (de $\mathrm{R} \$ 1.041,00$ a $\mathrm{R} \$ 1.750,00$ ), apenas $4 \%$. Nota-se que, dada a antigüidade desta imigração, há registros de bolivianos das Terras Baixas com rendimento acima de dez salários mínimos.

Para os provenientes das Terras Altas, embora seja elevada a proporção (cerca de $45 \%$ ) de imigrantes com até um salário mínimo (até $R \$ 350,00$ ), esta é inferior à dos nascidos nas Terras Baixas, enquanto é maior a participação daqueles com rendimento de 1 a 3 salários mínimos (45\%); seguem-se com proporção um pouco mais elevada, se comparada às Terras Baixas, os imigrantes com rendimento entre 3 e 10 salários mínimos.

Esses diferenciais estão também refletidos na distribuição dos bolivianos na cidade de Corumbá, com um rendimento nominal mensal dos responsáveis pelos domicílios bolivianos de $\mathrm{R} \$ 1.248,00$ no centro - onde há concentração de imigrantes das Terras Altas - e de $\mathrm{R} \$ 318,00$ no bairro Cristo Redentor - área de expansão da imigração boliviana nascida nas Terras Baixas.

\section{Considerações finais}

As análises advindas do levantamento de campo revelaram expressivos diferenciais entre as populações bolivianas imigrantes em Corumbá, segundo o agrupamento desses contingentes de acordo com o departamento de nascimento: Terras Baixas e Terras Altas.

Desde o primeiro momento da emigração esteve presente a seletividade migratória nas distintas populações de bolivianos

TABELA 7

Imigrantes bolivianos, por local de origem, segundo situação ocupacional Município de Corumbá - 2006

\begin{tabular}{lccc}
\hline Situação ocupacional & Terras Baixas & Terras Altas & Total \\
\hline Empregado & 42 & 8 & 50 \\
Autônomo por conta própria & 50 & 41 & 91 \\
Empregador & 1 & 1 & 2 \\
Profissional universitário autônomo & 2 & 0 & 2 \\
Dono de negócio familiar & 23 & 13 & 36 \\
Trabalhador em negócio familiar & 4 & 4 & 8 \\
Não sabe & 1 & 0 & 1 \\
Não se aplica & 151 & 21 & 172 \\
Total & $\mathbf{2 7 4}$ & $\mathbf{8 8}$ & $\mathbf{3 6 2}$ \\
\hline
\end{tabular}

Fonte: Encor 2006. Nepo/Unicamp-IRD/França.

TABELA 8

Imigrantes bolivianos, por local de origem, segundo rendimento médio mensal Município de Corumbá - 2006

\begin{tabular}{lccc}
\hline Rendimento & Terras Baixas & Terras Altas & Total \\
\hline Até $\mathrm{R} \$ 350,00$ & 110 & 29 & 139 \\
$\mathrm{R} \$ 351,00$ a $\mathrm{R} \$ 1.050,00$ & 42 & 29 & 71 \\
$\mathrm{R} \$ 1.051,00$ a $\mathrm{R} \$ 1.750,00$ & 7 & 4 & 11 \\
$\mathrm{R} \$ 1.751,00$ a $\mathrm{R} \$ 3.500,00$ & 5 & 2 & 7 \\
Mais de $\mathrm{R} \$ 3.501,00$ & 3 & 0 & 3 \\
Subtotal & $\mathbf{1 7 1}$ & $\mathbf{6 4}$ & $\mathbf{2 3 1}$ \\
Não sabe & 2 & 3 & 5 \\
Total & $\mathbf{2 7 4}$ & $\mathbf{8 8}$ & $\mathbf{3 6 2}$ \\
\hline
\end{tabular}

Fonte: Encor 2006. Nepo/Unicamp-IRD/França. 
que chegaram a Corumbá. Tais heterogeneidades imprimem características peculiares aos diferentes grupos de bolivianos residentes na cidade, diferenciando-os não apenas em termos econômicos e sociais, mas também na localização espacial de um mesmo contingente estrangeiro no destino migratório.

Pôde-se apreender que a migração ainda não é um processo uniformizante do grupo migrante no lugar de destino; a seletividade migratória desde a origem se re-territorializa, mantendo as condições de sua distribuição espacial que se define tanto pela fragmentação quanto pela concentração. A manutenção da coesão de cada grupo se dá pelas diferenças estabelecidas desde a origem. Mas, na migração, a coesão de cada grupo existe pela permanência de condicionantes capazes de se reproduzirem no lugar de destino. Esse processo de re-territorialização, além de reproduzir diferenças, alimenta o distanciamento social que na origem nem sempre existia, e que o

\section{Referências bibliográficas}

BLANCHARD, S. Être "colla" à Santa Cruz: identités et territoires des migrants andins à Santa Cruz de la Sierra (Bolivie). Thèse de Doctorat, Géographie. Paris, 2005.

CELTON, D.; DOMENACH H. La comunidad boliviana en Córdoba. Caracterización y proceso migratorio. Cordoba: Universidad de Córdoba, Orstom, 1998.

CORTES, G. Les boliviens à Buenos Aires: présence dans la ville, repères de la ville.Revue Européenne des Migrations Internationales, Poitiers, 17, p.119-146, 2001.

D'ANDREA, N. Effets de frontière, migrations et redistribution du peuplement en Bolivie: les dynamiques territoriales dans le département de Tarija. Thèse de doctorat en aménagement de l'espace, urbanisme. Université d'Aix en Provence, 2004.

El processo de urbanización en Bolivia 1992-2001. La Paz: INE-Codepo, 2004. contexto urbano e co-presença em Corumbá induzem.

A localização diferenciada (concentração e fragmentação) dos grupos no espaço de destino reflete duas lógicas: uma boliviana com base etno-lingüística; e outra brasileira com base nas desigualdades sociais e referente ao processo de urbanização e periferização.

A dinâmica urbana da cidade da fronteira tem que ser considerada em função de elementos da estrutura social do país de origem e não somente de destino.

Como observado, do ponto de vista econômico, são os collas os pioneiros do fluxo migratório para o Brasil, inclusive com expressiva inserção na sociedade de destino. Contudo, do ponto de vista da representação da estrutura social dessa migração, os cambas difundem um discurso que desqualifica o collas, mantendo em território brasileiro o estigma existente em certos lugares da origem, principalmente em Santa Cruz de la Sierra.

DOMENACH, H. et al. (Eds.). Movilidad y procesos migratorios en el espacio de frontera Argentina-Bolívia. Córdoba: Universidad Nacional de Córdoba, 2007.

IBGE. Censo Demográfico 2000. Rio de Janeiro, 2000.

Rio de Janeiro, 2007.

INSTITUTO NACIONAL DE ESTADÍSTICA. Bolivia: características sociodemográficas de la población. La Paz: INE, 2003.

ROUX, J.-C. La Bolivie orientale. Confins inexplorés, battues aux indiens et économie de pillage. Paris: L'Harmattan, 2000.

SECRETARÍA TÉCNICA DEL CONSEJO DE POBLACIÓN PARA EL DESARROLLO SOSTENIBLE (CODEPO). Estudio de la migración interna en Bolivia. La Paz: Codepo, 2004.

SILVA, A. S. D. Etnia, nação e regionalismos no jogo identitário entre os migrantes 
bolivianos em São Paulo. In: HEIDEMANN, H. D.; SILVA, A. S. D. (Eds.). Simpósio internacional migração: nação, lugar e dinâmicas territoriais. São Paulo: Humanitas/ UGI, 2007, p. 123-136.

Costurando sonhos. Trajetória de um grupo de imigrantes bolivianos em São Paulo. São Paulo: Paulinas Editora, 1997.

. Virgem/mãe/terra. Festas e tradições bolivianas na metrópole. São Paulo: Hucitec/Fapesp, 2003.

SOUCHAUD, S.; CARMO, R. L. D.; FUSCO, W. Mobilidade populacional e migração no Mercosul: a fronteira do Brasil com Bolívia e Paraguai. Teoria \& Pesquisa, São Carlos, XVI, p. 39-60, 2007.

SOUCHAUD, S.; MARTIN, C. Yacuiba, un islote del Chaco boliviano en la mundialización. In: DOMENACH, H.; CELTON, D.; ARZE, H.; HAMELIN, P. (Eds.). Movilidad y procesos migratorios en el espacio de frontera
Argentina-Bolivia. Córdoba: Universidad Nacional de Córdoba, 2007, p.55-94.

SOUCHAUD, S. Algumas considerações sobre a migração internacional transfronteiriça a partir do caso da migração boliviana em Corumbá, Mato Grosso do Sul. In: OSÓRIO, A.C.N.; PERREIRA, J.H.V.; OLIVEIRA, T.C.M. (Eds.). América Platina: textos escolhidos. Campo Grande: Editora da UFMS, 2008.

SOUCHAUD, S.; BAENINGER, R. Diferenciais da imigração boliviana em Corumbá: resultados de pesquisa de campo. In: SEMINARIO INTERNACIONAL DE ESTUDOS FRONTERIÇOS, 2008, Corumbá. Anais... Corumbá: Universidade Federal de Mato Grosso do Sul (UFMS), Campus do Pantanal, 2008.

SOUCHAUD, S.; FUSCO, W. Espaços migratórios e redes sociais da migração boliviana no Brasil: Corumbá e São Paulo. Campinas: Nepo/IRD, 2007 (Documentação da pesquisa), mimeo.

\section{Resumen}

Collas y cambas del otro lado de la frontera: aspectos de la distribución diferenciada de la inmigración boliviana en Corumbá, Mato Grosso del Sur

Este estudio busca presentar los resultados de la investigación de campo acerca de los bolivianos residentes en la ciudad de Corumbá - MS, destacando sus características. Se procuró captar las diferencias de la inmigración boliviana a la ciudad de Corumbá, identificando aspectos culturales, territoriales y étnico-lingüísticos de las áreas de origen que se reflejan en las diferencias socio-demográficas existentes - entre un mismo contingente inmigrante - en el lugar de destino: Corumbá/Brasil. Tales aspectos constituyen factores importantes para la lectura de la propia configuración urbana de la localización de la inmigración boliviana en Corumbá.

Palabras-clave: Migración internacional. Frontera. Bolivianos.

\section{Abstract \\ Collas and cambas from the other side of the border: factors of the unusual distribution of Bolivian immigration in Corumbá, State of Mato Grosso do Sul, Brazil}

This study discusses the findings of field research on Bolivian residents living in the city of Corumbá, Mato Grosso do Sul, Brazil, with special emphasis on their characteristics. The research was aimed at detecting the unusual aspects of Bolivian immigration to the city of Corumbá, identifying cultural, territorial and ethno-linguistic aspects of the areas of origin, which are reflected in the sociodemographic differences that exist within the same contingent 
of immigrants in their place of destination: Corumbá, Brazil. These factors are important for a reading of the urban characterization of Bolivian immigration in Corumbá.

Keywords: International migration. Border. Bolivian.

Recebido para publicação em 31/07/2008. Aceito para publicação em 14/11/2008. 